\title{
Editorial
}

\section{Advanced Cementitious Materials: Mechanical Behavior, Durability, and Volume Stability}

\author{
Doo-Yeol Yoo, ${ }^{1}$ Nemkumar Banthia, ${ }^{2}$ Kazunori Fujikake, \\ Paulo H. R. Borges, ${ }^{4}$ and Rishi Gupta ${ }^{5}$ \\ ${ }^{1}$ Department of Architectural Engineering, Hanyang University, 222 Wangsimni-ro, Seongdong-gu, Seoul 04763, \\ Republic of Korea \\ ${ }^{2}$ Department of Civil Engineering, The University of British Columbia, 6250 Applied Science Lane, Vancouver, BC, \\ Canada V6T $1 Z 4$ \\ ${ }^{3}$ Department of Civil and Environmental Engineering, National Defense Academy, Yokosuka 239 8686, Japan \\ ${ }^{4}$ Department of Civil Engineering, Federal Centre for Technological Education of Minas Gerais (CEFET-MG), \\ Av. Amazonas 7675, 30510-000 Belo Horizonte, MG, Brazil \\ ${ }^{5}$ Department of Civil Engineering, University of Victoria, 3800 Finnerty Road, Victoria, BC, Canada V8W $2 Y 2$
}

Correspondence should be addressed to Doo-Yeol Yoo; dyyoo@hanyang.ac.kr

Received 6 June 2017; Accepted 6 June 2017; Published 30 August 2017

Copyright (c) 2017 Doo-Yeol Yoo et al. This is an open access article distributed under the Creative Commons Attribution License, which permits unrestricted use, distribution, and reproduction in any medium, provided the original work is properly cited.

Several types of advanced cementitious materials, including fiber-reinforced cement composite, eco-friendly concrete including supplementary cementitious materials (i.e., fly ash, ground granulated blast furnace slag, and silica fume), geopolymer concrete, (ultra)high-performance concrete, and self-consolidating concrete, have been developed worldwide since the 1960s. Fiber-reinforced cement composite is suited for structures under flexure or tension due to its inhibition of crack propagation and widening through fiber bridging. Eco-friendly/geopolymer concrete became very important in construction technology after the UN Climate Change Conference held in 2015, since it can reduce carbon dioxide emissions from cement production. (Ultra)highperformance concrete may improve several shortcomings of ordinary concrete in terms of strength-to-weight ratio, ductility, durability, workability, and so forth, and also selfconsolidating concrete is an example of high-performance concrete improving workability.

This special issue aimed to provide a comprehensive overview on cementitious materials, including aspects related to mechanical behavior, durability, and time-dependent volume changes, such as shrinkage and creep. Authoritative review articles and original research papers describing recent findings in the field of advanced cementitious materials successfully covered the above topics. This special issue was also very competitive. In total, 58 scientific papers were submitted, and among them, only 14 papers were finally accepted for publication. Acceptance rate was approximately $24 \%$.

Several experimental and numerical papers addressed new research findings with regard to durability properties of concrete. K. Y. Ann et al. examined the effect of frost damage on the rate of chloride transport in ordinary concrete subjected to a rapid freeze-thaw cyclic environment. In their study, the chloride transport was accelerated by frost damage and it was more obvious at a lower cement content. The freezing condition also increased the volume of large capillary pores in ordinary concrete. K.-B. Park et al. numerically simulated the time-dependent chloride diffusion coefficients of concrete including ground granulated blast furnace slag. With an addition of the slag, the changes of total porosity, pore refinement on macro- and microscales due to filling effect, latent-hydraulic properties, and pozzolanic reaction were also analyzed. By comparing the numerical and experimental data, it was concluded that the proposed model is valid for concrete with different water-to-binder ratios, slag replacement ratios, and curing ages. H. J. Yang et al. evaluated the chloride transport in various types of high alumina cement mortar. An increase of $\mathrm{Al}_{2} \mathrm{O}_{3}$ content in the high alumina cement clinker led to an increase of diffusion 
coefficient and concentration of surface chloride due to the increase of chloride binding. But the pore distribution in the cement matrix was not influenced by the types of high alumina cement, except for macropores. An extensive literature review was also conducted by P. Azarsa and R. Gupta for a connection between the electrical resistivity of concrete and the deterioration processes like increase in permeability and corrosion of embedded steel.

The volume stability of cement paste and concrete was investigated by several researchers. B. Kucharczyková et al. introduced an advanced measurement equipment and procedure for simultaneous measurement of length changes, mass losses, acoustic responses, and temperature development. The cement composite's setting and hardening characteristics were evaluated by the continuous measurements of the relative length changes and mass losses. In addition, the formation of microcracks during the setting and hardening of the composites, substantially affecting the final mechanical properties, was possible to be determined using acoustic emission method. Y. Chen et al. examined the effects of amorphous nano- $\mathrm{SiO}_{2}$ on the early-age properties, such as consistency, setting time, strength, and chemical/autogenous shrinkages. The addition of nano-SiO2 resulted in higher consistency, significant reductions in setting times, higher early-age strength, and higher chemical/autogenous shrinkages. The implications of concrete age and creep on the ultimate load carrying capacity of concrete-filed steel tube columns were also reported by $\mathrm{H}$. Y. Wang et al. based on both experimental tests and numerical analyses. H. Xiong et al. investigated the strain behavior of external thermal insulation cladding systems with Glazed Hollow Beads thermal insulation mortar under hygrothermal cycles. Their test results indicated that the finishing coat shrank at early stage, while the finishing coat tended to expand and became damaged at later stage. The crack length and width on the finishing coat increased with age, but the cracks stopped growing around 70 cycles.

Some other properties, including mechanical property, rheological property, hydration activity, and pore structure, of cement paste and concrete were also reported. R. Chakravarthy et al. tried to develop ductile high volume fly ash concrete including steel, polypropylene (PP), and basalt fibers. In their study, a significant improvement of mechanical properties of high volume fly ash concrete was obtained by including hybrid fibers (i.e., $1 \%$ steel fiber, $0.75 \%$ PP fiber, and $0.75 \%$ basalt fiber). A limiting combination of $3 \%$ overall fibers was determined based on the workability of concrete. K.-K. Yun et al. mainly evaluated the pumpability of wet-mix shotcrete including various admixtures, that is, silica fume, fly ash, ground granulated blast furnace slag, metakaolin, and steel fibers based on rheological properties. The addition of silica fume and metakaolin led to satisfactory pumpability, whereas those of fly ash and steel fibers failed to meet the pumping criteria at normal pump pressure. On the other hand, the use of ground granulated blast furnace slag had no significant effect on the pumpability. J. H. Kim et al. introduced the alpha test to examine the performance of polycarboxylate-based high-range water-reducing admixture. To overcome some drawbacks of the mini-slump flow test, the channel flow test was proposed. The final spread and the time to get the stoppage of the spread were measured, and a model converting them into rheological properties was developed. Y. Gao et al. modeled a pore structure in cement paste by means of the recently proposed solid mass fractal model and an enhanced Maxwell homogenization method to determine the associated ionic diffusivity. They verified the developed model by comparing it with experimental results, that is, mercury intrusion porosimetry and rapid chloride migration. S. K. Kim et al. suggested a method for sustainable development of cement industry as well as waste recycling on a national scale that was replacing a portion of cement with a high quality liquid crystal display (LCD) processing waste glass (LPWG) powder. For this, they investigated both fresh and hardened properties of concrete with various amounts of the LPWG powder. Lastly, the reasons why $\mathrm{f}-\mathrm{CaO}$ in basic oxygen furnace slag is expanded and shows slow hydration activity were studied by R. Jia and J. Liu based on simulated experiments.

The guest editors hope that readers of this special issue can obtain useful experimental and numerical results and discover recent research trends regarding advanced cementitious materials. Furthermore, we wish that their academic curiosities and difficulties can be solved by investigating the valuable research results in this special issue containing both experimental and numerical developments. This publication considers a wide range of disciplines, including civil, architectural, and chemical engineering, and may appeal to the scientists and engineers.

Doo-Yeol Yoo Nemkumar Banthia Kazunori Fujikake Paulo H. R. Borges Rishi Gupta 

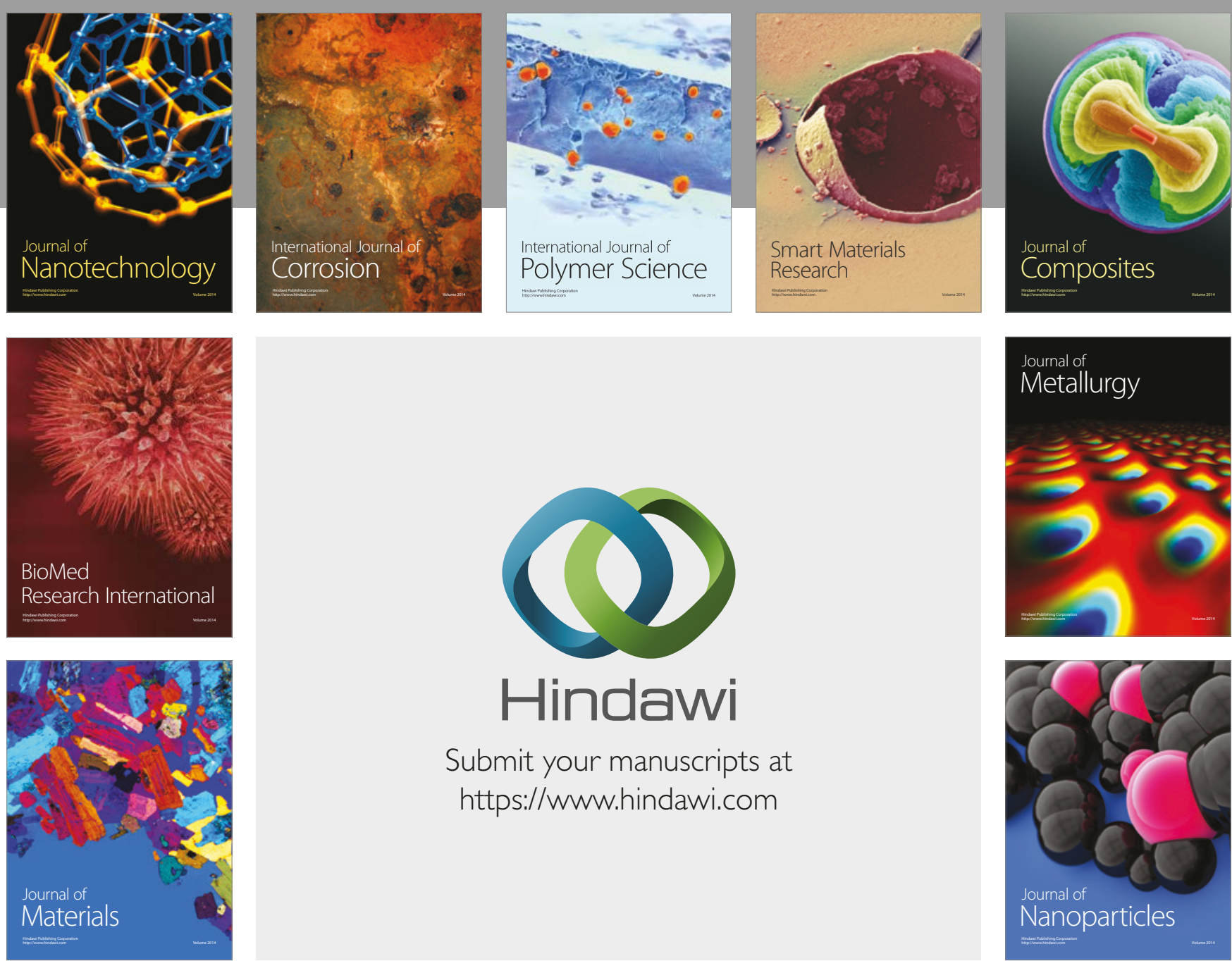

\section{Hindawi}

Submit your manuscripts at

https://www.hindawi.com
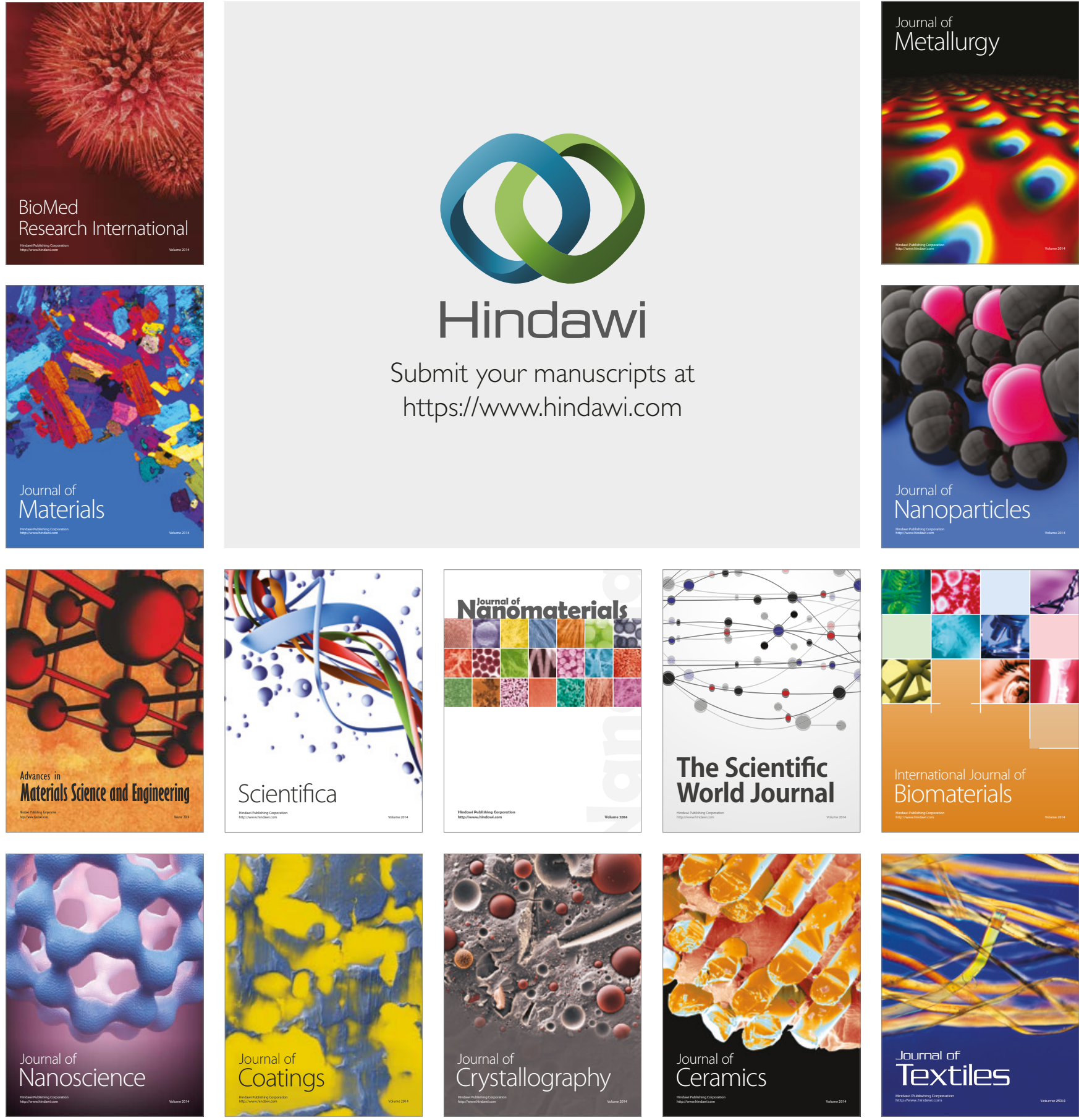

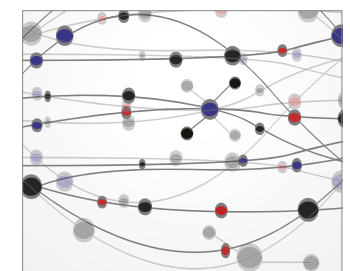

The Scientific World Journal
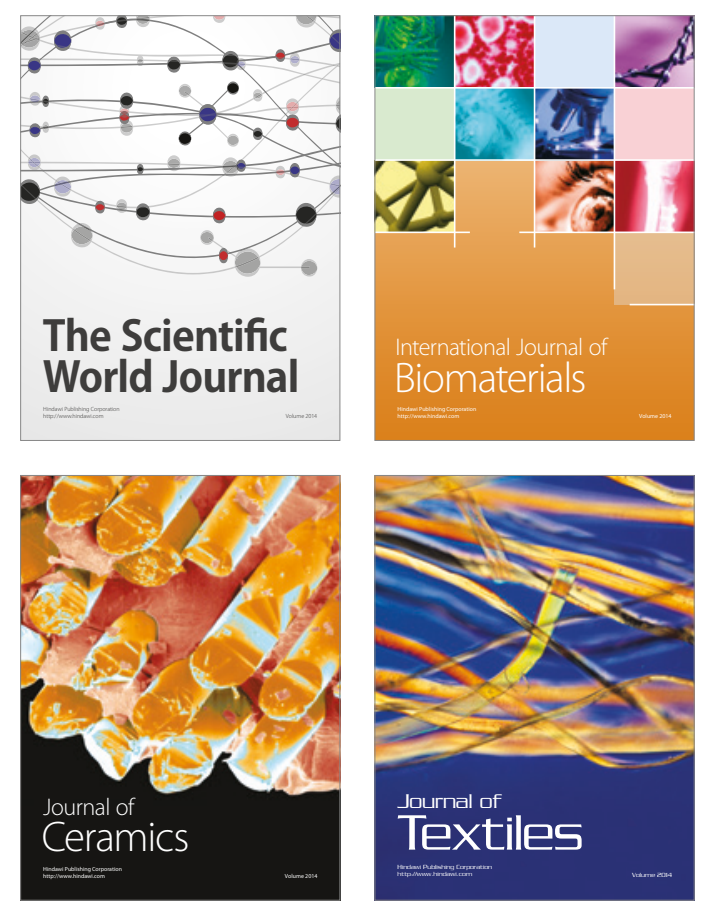